\title{
Sorption properties of activated carbons obtained from corn cobs by chemical and physical activation
}

\author{
Justyna Kaźmierczak • Piotr Nowicki • Robert Pietrzak
}

Received: 31 October 2012 / Accepted: 3 December 2012 / Published online: 13 December 2012

(C) The Author(s) 2012. This article is published with open access at Springerlink.com

\begin{abstract}
The paper presents results of a study on obtaining activated carbon from common corn cobs and on its use as adsorbent for removal of pollution from liquid and gas phases. The crushed precursor was subjected to pyrolysis at 500 and $800^{\circ} \mathrm{C}$ in argon atmosphere and next to physical or chemical activation by $\mathrm{CO}_{2}$ and $\mathrm{KOH}$ respectively. The effect of pyrolysis conditions and activation method on the physicochemical properties of the materials obtained was tested. The sorption properties of the carbonaceous adsorbents obtained were characterized by determination of nitrogen dioxide and hydrogen sulphide sorption from gas stream in dry and wet conditions as well as by iodine and methylene blue removal from aqueous solution.

The final products were microporous activated carbons of well-developed surface area varying from 337 to $1213 \mathrm{~m}^{2} / \mathrm{g}$ and showing diverse acid-base character of the surface. The results obtained in our study have proved that a suitable choice of the activation procedure for corn cobs permits production of cheap adsorbents with high sorption capacity toward toxic gases of acidic character as well as different pollutants from liquid phase.
\end{abstract}

Keywords Waste corn cobs - Activated carbons .

Pyrolysis, activation $\cdot \mathrm{NO}_{2} / \mathrm{H}_{2} \mathrm{~S}$ removal $\cdot$ Iodine and methylene blue adsorption

J. Kaźmierczak · P. Nowicki · R. Pietrzak $(\bowtie)$

Laboratory of Applied Chemistry, Faculty of Chemistry, Adam

Mickiewicz University in Poznań, ul. Umultowska 89b,

61-614 Poznań, Poland

e-mail: pietrob@amu.edu.pl

J. Kaźmierczak

e-mail: justykaz@amu.edu.pl

P. Nowicki

e-mail: piotrnow@amu.edu.pl

\section{Introduction}

Agricultural production and processing of agricultural products has always been associated with generation of large amounts of post-production wastes, such as corn cobs (Cao et al. 2006), cotton stems (Jiang and Chen 2011), cherry stones (Olivares-Marín et al. 2009), olive stones (Kutahyalıand Eral 2010), grape stones (Özçimen and ErsoyMeriçboyu 2009), apricot stones (Soleimani and Kaghazchi 2008), avocado stones (Elizalde-González et al. 2007), orange peel (Rosas et al. 2010), mango peel (Foo and Hameed 2012), pomelo peal (Foo and Hameed 2011) etc. The wastes can on certain conditions be treated as side products or as pure waste. Many side products contain valuable elements and minerals, but their economic value is lower than the cost of collection, transport and processing for beneficial use. That is why they are also usually discarded as waste.

For instance, in the 1980s the production of corn highly increased, which also meant a high increase in the amount of corn cobs. To produce each $100 \mathrm{~kg}$ of corn, about $18 \mathrm{~kg}$ of cobs are obtained and they are usually treated as waste. There have been attempts of processing them into fertilisers, soil quality improving agents, bedding material for animals, a source of fibre in fodder and a source of energy in combustion (Tsai et al. 2001). In recent years much interest has been paid to the use of corn cobs for production of activated carbon (Chang et al. 2000; Sych et al. 2012; Tsai et al. 1998).

Activated carbons are characterised by high degree of porosity and have very well developed surface area reaching a few thousand square meters per gram (Sevilla et al. 2011). Besides carbon they can contain other elements such as hydrogen, nitrogen, sulphur and oxygen, which are either the remains from the initial material or have been bonded to carbon in the process of production. The use of carbon adsorbents for removal of pollutants from the liquid and gas 
phase is much more effective than with the use of other methods (Solisio et al. 2001). Activated carbons can be used for adsorption of organic (Deryło-Marczewska et al. 2004) and inorganic (Lee and Reucroft 1999) compounds, occurring in the dissociated and molecular forms. The possibility of adsorption of such a wide range of materials is related to the presence of a variety of adsorption centres of different strength, localised mainly on the surface of micropores reaching of up to $2.0 \mathrm{~nm}$ in size (micropores according to IUPAC classification) (Bansal and Goyal 2005).

Recently the use of agricultural waste as precursors of activated carbons have enjoyed much interest because of much lower cost of their production than that of carbon production from coal or wood.

The main aim of this study was to obtain carbonaceous adsorbents from corn cobs by pyrolysis and physical or chemical activation, and evaluate the use of the chars and activated carbons produced as sorbents of pollutants from gas and liquid phase.

\section{Experimental}

\subsection{Preparation of activated carbons}

The starting corn cobs (CC) were cut up to rings and next subjected to pyrolysis. This process was carried out in a horizontal furnace under a stream of argon with a flow rate of $0.170 \mathrm{~L} / \mathrm{min}$. The sample was heated $\left(10^{\circ} \mathrm{C} / \mathrm{min}\right)$ from room temperature to the final pyrolysis temperature of 500 (CC5) and $800{ }^{\circ} \mathrm{C}$ (CC8). In the final pyrolysis temperature, samples were kept for $60 \mathrm{~min}$ and then cooled down. The products of pyrolysis were next subjected to physical (PA) or chemical activation (CA). Physical activation was carried out at temperature of $800^{\circ} \mathrm{C}$, under a stream of carbon dioxide with a flow rate of $0.250 \mathrm{~L} / \mathrm{min}$, for $30 \mathrm{~min}$. Chemical activation by $\mathrm{KOH}$ was preformed with an alkali/char weight ratio of $2 / 1$ for $30 \mathrm{~min}$, in argon atmosphere (flow rate $0.330 \mathrm{~L} / \mathrm{min}$ ).

\subsection{Analytical procedures}

The elemental analysis of the starting corn cobs, chars and activated carbons were performed on an elemental analyser CHNS Vario EL III (Elementar Analysensysteme GmbH, Germany).

Characterisation of the pore structure of chars and activated carbons was performed on the grounds of lowtemperature nitrogen adsorption-desorption isotherms measured on Autosorb iQ surface area analyzer (Quantachrome Instruments, USA). On the grounds of results of the measurements surface area, total pore volume and pore diameter were determined. The $S_{\mathrm{BET}}$ surface area was assessed within the range of relative pressures from 0.05 to 0.3 . The total pore volume $\left(V_{t}\right)$ was calculated by measuring the amount of liquid nitrogen adsorbed at a relative pressure $p / p_{0}=0.99$. The average pore diameter $(d)$ was calculated from equation $d=4 V_{t} / S_{\mathrm{BET}}$. Moreover micropore volume and area as well as external surface area were calculated using t-plot method.

SEM images of chars and activated carbons were obtained using a scanning electron microscope made by PHILIPS (Netherlands) in the following conditions: accelerating voltage of $15 \mathrm{kV}$, working distance of $14 \mathrm{~mm}$ and digital image recording by DISS.

The content of surface oxygen functional groups were determined according to the Boehm method (Boehm et al. 1964).

The $\mathrm{pH}$ of chars and activated carbons was measured using the following procedure: a portion of $0.4 \mathrm{~g}$ the sample of dry chars and activated carbons powder was added to $20 \mathrm{~mL}$ of distilled water and the suspension was stirred overnight to reach equilibrium. Then $\mathrm{pH}$ of suspension was measured.

\subsection{Adsorption studies}

\subsubsection{Adsorption from gas phase}

The chars and activated carbons obtained were tested as adsorbents against two adsorbates-hydrogen sulphide and nitrogen dioxide. The tests were performed in dry (D) and wet (W) conditions (70\% humidity). Moreover, two variants of $\mathrm{H}_{2} \mathrm{~S}$ adsorption were used: the sample was wetted by the air of $70 \%$ humidity for 30 minutes and then the sorption tests were performed either in dry (MD) or in wet (MW) conditions.

The samples (in the form of granules of $0.75-1.5 \mathrm{~mm}$ in diameter) were packed into a glass column (length $300 \mathrm{~mm}$, internal diameter $9 \mathrm{~mm}$, bed volume $3 \mathrm{~cm}^{3}$ ). Dry or moist air with $0.1 \%$ of $\mathrm{NO}_{2}$ or $\mathrm{H}_{2} \mathrm{~S}$ was passed through the bed of the adsorbent at $0.450 \mathrm{~L} / \mathrm{min}$. The breakthrough of $\mathrm{H}_{2} \mathrm{~S}$ or $\mathrm{NO}_{2}$ were monitored using Q-RAE PLUS PGM-2000/2020 with electrochemical sensors. The tests were stopped at the breakthrough concentration of $100 \mathrm{ppm}$ (in case of $\mathrm{H}_{2} \mathrm{~S}$ ) or $20 \mathrm{ppm}$ (for $\mathrm{NO}_{2}$ ), because of the electrochemical sensor limits. The interaction capacities of each sorbent in terms of milligram of $\mathrm{H}_{2} \mathrm{~S}$ or $\mathrm{NO}_{2}$ per gram of adsorbent were calculated by integration of the area above the breakthrough curves, and from the toxic gas concentration in the inlet gas, flow rate, breakthrough time and mass of sorbent. Additionally to check the $\mathrm{NO}_{2}$ reduction, the concentration of $\mathrm{NO}$ in the system was also monitored till $200 \mathrm{ppm}$.

\subsubsection{Adsorption from liquid phase}

The iodine sorption ability of the chars and activated carbons, was determined according to the ASTM D4607-94 
Standard (2006). This method permits estimation of the adsorbents ability to remove substances whose molecules have the size close to that of iodine molecules, so of diameters close to $1 \mathrm{~nm}$, from the liquid phase.

Determination of the methylene blue (MB) adsorption was performed using the following procedure: samples of the prepared chars and activated carbons of equal masses of $0.2 \mathrm{~g}$ were added to $100 \mathrm{~mL}$ of $\mathrm{MB}$ solution with initial concentrations of $100 \mathrm{mg} / \mathrm{L}$ and the suspension was stirred for $24 \mathrm{~h}$ to reach equilibrium. The concentrations of $\mathrm{MB}$ in the solution before and after adsorption were determined using a double beam UV-Visible spectrophotometer (Cary Bio 100, Varian) at $660 \mathrm{~nm}$.

\section{Results and discussion}

\subsection{Elemental composition of the chars and activated carbons}

As corn cobs are characterised by very low content of carbon and high content of volatiles (Table 1), at first they were subjected to pyrolysis at different temperatures. The products of pyrolysis were chars CC5 and CC8, characterised by much higher carbon content, a bit higher content of ashes

Table 1 Elemental analysis of the corn cobs, chars and activated carbons obtained and the yield of pyrolysis and activation processes (wt.\%)

\begin{tabular}{lllllllll}
\hline Sample & Ash & $\mathrm{VM}^{*}$ & $C^{\text {daf } * *}$ & $H^{\text {daf }}$ & $N^{\text {daf }}$ & $S^{\text {daf }}$ & $O^{\text {daf*** }}$ & Yield \\
\hline CC & 1.0 & 64.6 & 43.8 & 6.2 & 1.7 & 0.0 & 48.3 & - \\
CC5 & 2.9 & 17.3 & 85.6 & 3.1 & 0.4 & 0.0 & 10.8 & 26.1 \\
CC8 & 7.0 & 11.6 & 85.5 & 0.9 & 0.3 & 0.0 & 13.3 & 16.6 \\
CC5PA & 4.4 & - & 86.5 & 1.5 & 0.8 & 0.0 & 11.2 & 76.7 \\
CC8PA & 7.6 & - & 89.9 & 0.7 & 0.6 & 0.0 & 8.8 & 79.1 \\
CC5CA & 0.6 & - & 86.4 & 0.9 & 0.7 & 0.0 & 12.0 & 62.1 \\
CC8CA & 0.7 & - & 91.1 & 0.6 & 0.6 & 0.0 & 7.8 & 67.0 \\
\hline
\end{tabular}

${ }^{*}$ volatile matter; ${ }^{* *}$ dry-ash-free basis; ${ }^{* * *}$ determined by difference but a much lower content of volatiles than the initial material. Changes in the above contents significantly depended on the temperature of pyrolysis and were much more pronounced for sample CC8.

The increase in the content of $C^{\text {daf }}$ is accompanied with a clear decrease in the content of the other elements, in particular hydrogen and oxygen. A considerable decrease in $N^{\text {daf }}$ as a result of pyrolysis suggests that nitrogen occurred mainly in the form of thermally unstable groups. As follows from the data presented in Table 1, both the precursor and obtained from it chars and activated carbons, do not contain sulphur in their structure, which is very favourable from the ecological and technological points of view.

Further analysis of the data from Table 1 indicates that irrespectively of the variant used, the process of activation leads to further changes in the structure of carbonaceous material. The products of activation, in particular those obtained from char $\mathrm{CC} 8$, are characterised by a greater contribution of carbon and much lower content of $H^{\text {daf }}$ than the corresponding chars. The content of oxygen in the activated carbons changes in a different way: in samples CC8PA and CC8CA obtained by activation of char CC8, the content of oxygen decreases, while in samples CC5PA and CC5CA it slightly increases. The content of nitrogen is a bit different than in the products of pyrolysis. An important feature is a very low content of ashes in the activated carbon samples obtained $\left(A^{d}\right)$, the only exception is the sample obtained by physical activation of CC8 char which has a rather high content of mineral substances.

\subsection{Textural parameters of chars and activated carbons}

As follows from the data presented in Table 2, the carbon samples obtained by physical and chemical activation of corn cobs show a variety of textural parameters depending considerably on the temperature of pyrolysis and the variant of activation. Physical activation of chars did not allow proper development of the porous structure. The surface areas of carbons obtained by pyrolysis of corn cobs and activated by physical methods were 352 and $566 \mathrm{~m}^{2} / \mathrm{g}$, while

Table 2 Textural parameters of chars and activated carbons obtained

\begin{tabular}{lccllllll}
\hline Sample & $\begin{array}{l}\text { Total surface } \\
\text { area }\left[\mathrm{m}^{2} / \mathrm{g}\right]\end{array}$ & $\begin{array}{l}\text { Micropore } \\
\text { area }\left[\mathrm{m}^{2} / \mathrm{g}\right]\end{array}$ & $\begin{array}{l}\text { External } \\
\text { area }\left[\mathrm{m}^{2} / \mathrm{g}\right]\end{array}$ & $\begin{array}{l}\text { Total pore } \\
\text { volume }\left[\mathrm{cm}^{3} / \mathrm{g}\right]\end{array}$ & $\begin{array}{l}\text { Micropore } \\
\text { volume }\left[\mathrm{cm}^{3} / \mathrm{g}\right]\end{array}$ & $\begin{array}{l}\text { Mesopore } \\
\text { volume }\left[\mathrm{cm}^{3} / \mathrm{g}\right]\end{array}$ & $\begin{array}{l}V_{\text {mic }} / V_{t} \\
\begin{array}{l}\text { Average pore } \\
\mathrm{diameter}[\mathrm{nm}]\end{array}\end{array}$ \\
\hline CC5 & 19 & 8 & 10.8 & 0.026 & 0.002 & 0.024 & 0.08 & 5.56 \\
CC8 & 43 & 34 & 7.6 & 0.05 & 0.02 & 0.03 & 0.02 & 0.40 \\
CC5PA & 352 & 337 & 14.9 & 0.21 & 0.19 & 0.03 & 0.90 & 2.44 \\
CC8PA & 566 & 552 & 13.5 & 0.33 & 0.30 & 0.10 & 0.91 & 2.30 \\
CC5CA & 1213 & 1164 & 49.1 & 0.73 & 0.63 & 0.03 & 0.86 & 2.42 \\
CC8CA & 747 & 735 & 12.4 & 0.43 & 0.40 & 0.93 & 2.29 \\
\hline
\end{tabular}


Fig. 1 SEM images of the chars and activated carbons
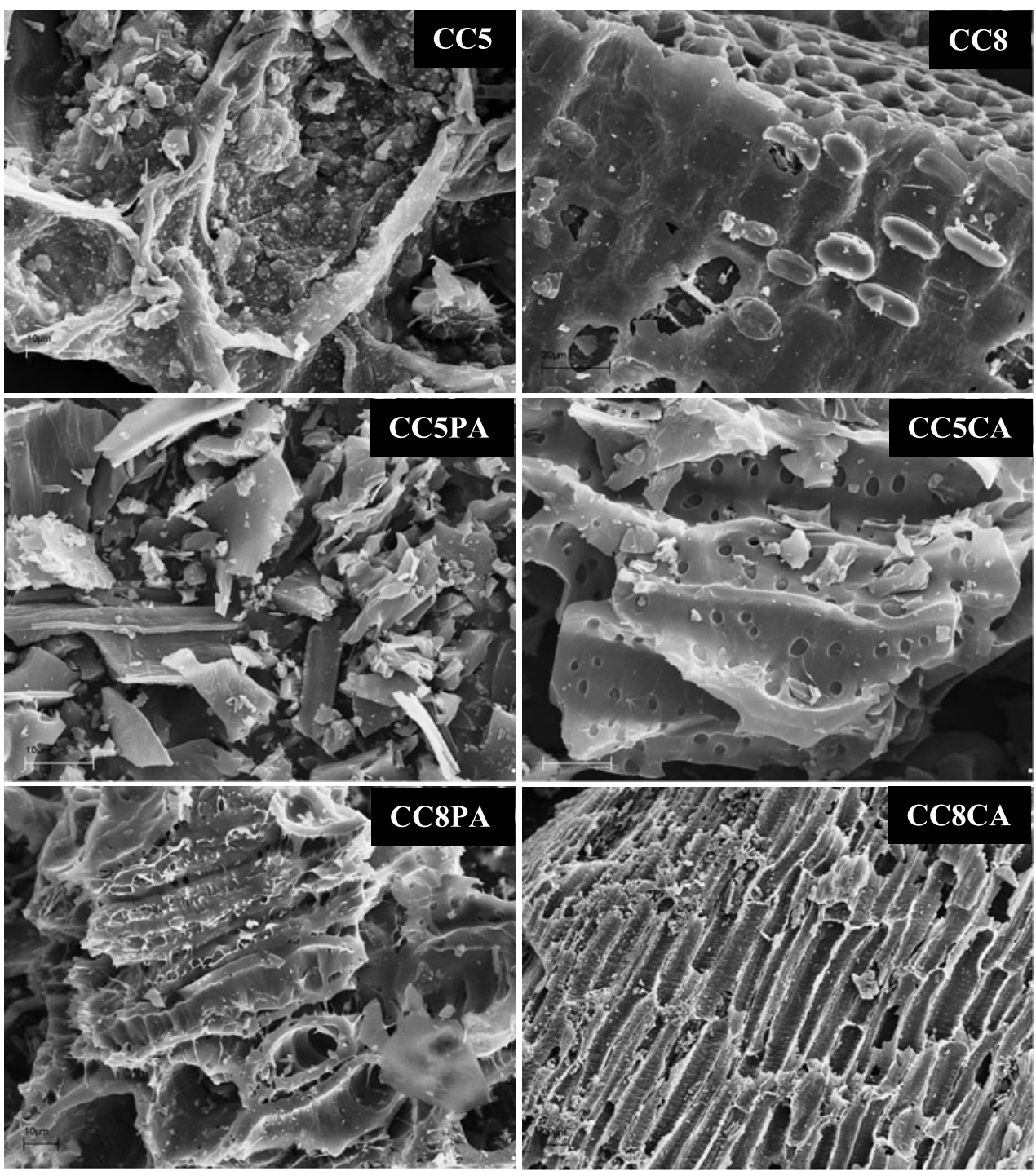

their pore volumes were 0.19 and $0.30 \mathrm{~cm}^{3} / \mathrm{g}$, respectively. As expected, much more effective in development of the porous structure was the chemical activation. The samples obtained in this way were characterised by $2-3$ times larger surface area and total pore volume than those activated by carbon dioxide.

As mentioned above, also the temperature of pyrolysis affected the parameters of carbon samples activated by $\mathrm{CO}_{2}$ or $\mathrm{KOH}$. For the samples obtained by physical activation, the higher the pyrolysis temperature the more developed the porous structure, but for the samples obtained by chemical activation the reverse relation was true.

All the activated carbon samples have microporous structure as the contribution of micropores in the total pore volume in them varies in the range 86-93\%. The other pores are mesopores of diameters varying in the range 2.29-2.47 $\mathrm{nm}$. To illustrate the structure of the samples obtained their SEM images are presented in Fig. 1. The SEM images confirm significant differences between the chars obtained by pyrolysis of corn cobs and the products obtained by their physical and chemical activations. The materials differ significantly in the number, shape, size and arrangement of pores.

\subsection{Acid-base properties of the chars and activated carbons}

According to the data presented in Table 3, the acid-base properties of the adsorbents are very different. The $\mathrm{pH}$ of the samples varies from 5.0 to 10.5 , while the content of oxygen surface groups varies from 1.04 to $1.83 \mathrm{mmol} / \mathrm{g}$. Both chars and the carbon samples obtained by their physical activation (CC5PA and CC8PA) have clearly alkaline surface character, of $\mathrm{pH}$ 9.5. The samples obtained by chemical activation have surfaces of acidic character, of $\mathrm{pH}$ close to 5 .

The adsorbents differ not only in the amount of surface oxygen groups but also in their type. Two samples CC5CA and CC8CA have surfaces with dominant presence of acidic 

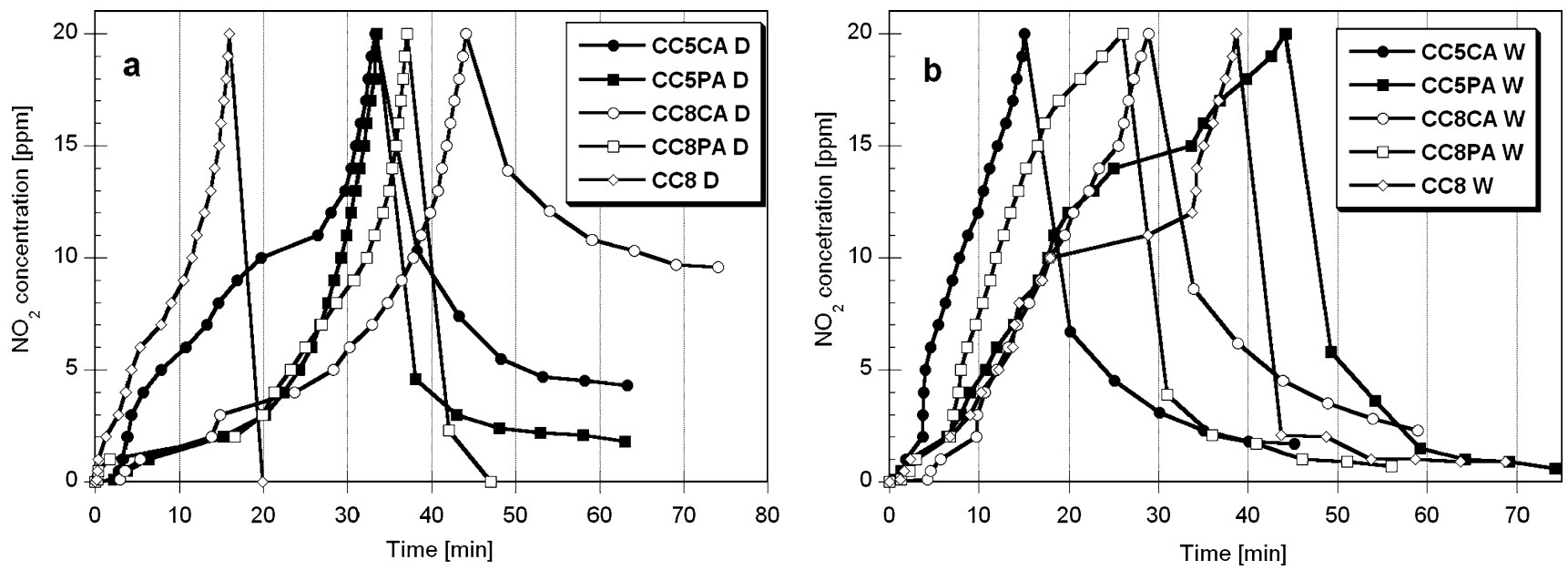

Fig. $2 \mathrm{NO}_{2}$ adsorption/desorption curves for the chars and activated carbons studied in dry (a) and wet (b) conditions

Table 3 Acid base properties of the chars and activated carbons obtained

\begin{tabular}{lrlll}
\hline Sample & $\mathrm{pH}$ & $\begin{array}{l}\text { Acidic } \\
\text { groups } \\
{[\mathrm{mmol} / \mathrm{g}]}\end{array}$ & $\begin{array}{l}\text { Basic groups } \\
{[\mathrm{mmol} / \mathrm{g}]}\end{array}$ & $\begin{array}{l}\text { Total content of } \\
\text { surface oxides } \\
{[\mathrm{mmol} / \mathrm{g}]}\end{array}$ \\
\hline CC5 & 9.8 & 0.00 & 1.04 & 1.04 \\
CC8 & 10.5 & 0.16 & 1.51 & 1.67 \\
CC5PA & 9.5 & 0.00 & 1.83 & 1.83 \\
CC8PA & 10.0 & 0.08 & 1.72 & 1.80 \\
CC5CA & 5.2 & 1.23 & 0.35 & 1.58 \\
CC8CA & 5.0 & 1.61 & 0.08 & 1.69 \\
\hline
\end{tabular}

groups, while samples CC8PA and CC5PA have surfaces with dominant basic groups.

Thus, the type and number of surface oxygen groups depend first of all on the variant of activation and the temperature of pyrolysis of the initial material. The highest total content of surface functional groups was observed for the samples obtained by physical activation of both chars, while the lowest for CC5. The increase in the temperature of pyrolysis from 500 to $800{ }^{\circ} \mathrm{C}$ favours the generation of a greater amount of basic groups and a smaller number of acidic groups. The temperature of pyrolysis also influences the amount of functional groups in the products of activation, which follows from the fact that all samples obtained from activation (physical or chemical) of char CC5 have a lower number of groups of acidic character and a greater number of groups of basic character than analogous adsorbents obtained from char CC8.

\subsection{Sorption capacities of the chars and activated carbons toward nitrogen dioxide}

As follows from Table 4, only sample CC5 shows no sorption capacity towards nitrogen dioxide both in dry and wet conditions. This fact is most probably a consequence of
Table $4 \mathrm{NO}_{2}$ breakthrough capacities of the chars and activated carbons obtained $\left(\mathrm{mg} / \mathrm{g}_{\mathrm{ads}}\right)$

\begin{tabular}{lcc}
\hline Sample & $\begin{array}{l}\text { Dry conditions } \\
{[\mathrm{mg} / \mathrm{g}]}\end{array}$ & $\begin{array}{l}\text { Wet conditions } \\
{[\mathrm{mg} / \mathrm{g}]}\end{array}$ \\
\hline CC5 & 0.0 & 0.0 \\
CC8 & 12.8 & 25.9 \\
CC5PA & 26.2 & 18.3 \\
CC8PA & 35.4 & 14.4 \\
CC5CA & 40.6 & 17.0 \\
CC8CA & 48.4 & 28.0 \\
\hline
\end{tabular}

poorly developed porous structure of the product of pyrolysis and a small amount of oxygen functional groups. The increase in the pyrolysis temperature to $800^{\circ} \mathrm{C}$ resulted in an increase in the sorption capacity as char CC8 in dry and wet conditions adsorbs $12.8 \mathrm{mg} / \mathrm{g}$ and $25.9 \mathrm{mg} / \mathrm{g} \mathrm{NO}_{2}$, respectively.

Table 4 data show that the adsorption capacities of the activated carbons obtained towards nitrogen dioxide differ depending on the temperature of pyrolysis, type of activation and conditions of adsorption. In contrast to char $\mathrm{CC} 8$, all activated carbons show much greater sorption capacities when adsorption takes place in dry conditions. The most effective adsorbent, both in dry and wet conditions, was CC8CA obtained by chemical activation of char CC8. The least effective in removal of nitrogen dioxide in dry and wet conditions was CC5PA sample, obtained by physical activation of char CC5. Also the temperature of pyrolysis influences the efficiency of nitrogen dioxide removal by the activated carbon samples obtained. The samples obtained by physical and chemical activation of char CC8 showed higher sorption capacity towards $\mathrm{NO}_{2}$ than the analogous materials obtained by activation of $\mathrm{CC} 5$ char.

The character of adsorption-desorption curves obtained from the measurements in dry conditions (Fig. 2(a)) implies 
that adsorption of $\mathrm{NO}_{2}$ on all samples runs by very similar mechanisms. The differences are revealed only in the desorption part of the curve. For CC8 char and carbon samples activated with $\mathrm{CO}_{2}$ the concentration of $\mathrm{NO}_{2}$ rapidly decreases after its supply has been cut off, while for the carbon samples activated with $\mathrm{KOH}$ the concentration of $\mathrm{NO}_{2}$ decreases very slowly and remains at a high level for a long time, especially for CC8CA. This fact suggests that on CC8 and the physically activated carbon $\mathrm{NO}_{2}$ is predominantly chemisorbed, while the main process taking place on the chemically activated carbon is physisorption. These observations can be related to the presence of basic oxygen groups on the surface of CC8, CC5PA and CC8PA, which can react with $\mathrm{NO}_{2}$, forming permanent bonds.

Much less important is the effect of textural parameters on the sorption properties of the samples studied. As follows from the results of measurements, the physically activated carbon show similar sorption properties to those of chemically activated samples, especially in wet conditions, despite much smaller surface area and pore volume (Table 2). This observation suggests that the chemical character of the surface also has considerable influence on the abilities of $\mathrm{NO}_{2}$ removal. The samples activated by $\mathrm{CO}_{2}$ contain large amounts of oxygen functional groups of basic character and their presence can explain their high sorption capacity towards nitrogen dioxide.

The adsorption-desorption isotherms obtained upon $\mathrm{NO}_{2}$ adsorption in wet conditions have different character. As follows from Fig. 2(b), the presence of steam in the system imposes certain changes in the adsorption curves of the majority of samples and hence in the mechanism of nitrogen dioxide adsorption, especially for the samples activated with $\mathrm{KOH}$. A comparison of the sections of isotherms corresponding to desorption, presented in Fig. 2(a) and 2(b), reveals that upon desorption in wet conditions (in contrast to the process in dry conditions) for all adsorbents studied

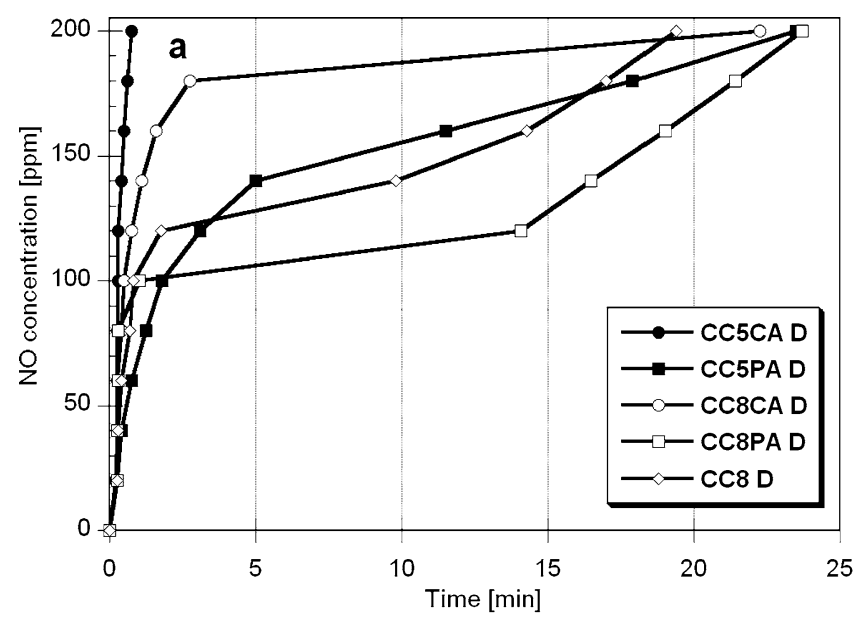

a rapid decrease in $\mathrm{NO}_{2}$ concentration takes place after its supply has been cut off.

Unfortunately, $\mathrm{NO}_{2}$ adsorption on the materials studied is accompanied by its reduction to NO. As indicated by the data from Fig. 3, and mainly by the fact that the maximum concentration of NO (200 ppm) is achieved in a much shorter time in the presence of water in the system, the reduction of $\mathrm{NO}_{2}$ is more efficient in wet conditions. High intensity of $\mathrm{NO}_{2}$ reduction in wet conditions can be the reason for much poorer sorption capacity. The nitrogen (II) oxide formed as a result of reduction can also be adsorbed on the surface and in the porous structure of the materials studied and in this way decrease their sorption capacity towards $\mathrm{NO}_{2}$. These observations confirm that the mechanisms of $\mathrm{NO}_{2}$ adsorption in dry and wet conditions are different.

\subsection{Sorption abilities of the chars and activated carbons toward $\mathrm{H}_{2} \mathrm{~S}$}

Similarly as in the case of $\mathrm{NO}_{2}$ adsorption, merely the CC8 char shows some sorption ability toward $\mathrm{H}_{2} \mathrm{~S}$. Analysis of the data given in Table 5 reveals that only the activated carbons obtained by physical activation of chars CC5 and CC8

Table $5 \mathrm{H}_{2} \mathrm{~S}$ breakthrough capacities of chars and activated carbons obtained $\left(\mathrm{mg} / \mathrm{g}_{\text {ads }}\right)$

\begin{tabular}{lcrrrr}
\hline Sample & \multicolumn{2}{l}{$\begin{array}{l}\text { Dry conditions } \\
{[\mathrm{mg} / \mathrm{g}]}\end{array}$} & & \multicolumn{2}{c}{ Wet conditions $[\mathrm{mg} / \mathrm{g}]$} \\
\cline { 2 - 3 } \cline { 6 - 6 } & $\mathrm{D}$ & $\mathrm{MD}$ & & $\mathrm{W}$ & $\mathrm{MW}$ \\
\hline CC5 & 0.0 & 0.0 & & 0.0 & 0.0 \\
CC8 & 6.7 & 9.5 & & 8.7 & 7.8 \\
CC5PA & 16.5 & 19.7 & & 18.0 & 10.8 \\
CC8PA & 19.5 & 49.2 & & 45.1 & 29.4 \\
CC5CA & 5.0 & 5.4 & & 6.8 & 5.0 \\
CC8CA & 4.1 & 6.1 & 6.3 & 4.7 \\
\hline
\end{tabular}

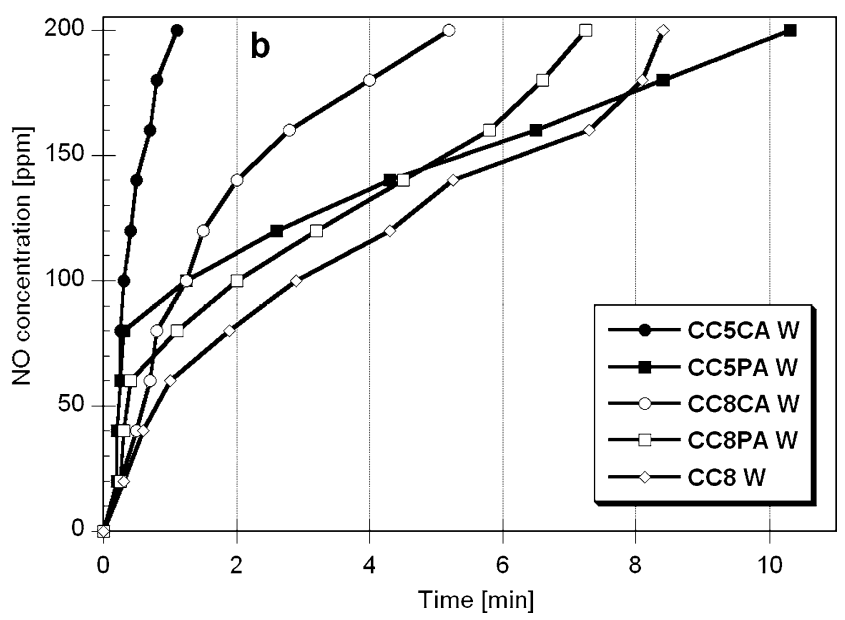

Fig. 3 Curves illustrating $\mathrm{NO}$ concentration changes during $\mathrm{NO}_{2}$ adsorption is dry (a) and wet (b) conditions 
have higher adsorption capacity towards hydrogen sulphide than $\mathrm{CC} 8$ char. The most effective adsorbent of $\mathrm{H}_{2} \mathrm{~S}$ proved to be CC8PA, whose sorption capacity towards hydrogen sulphide in dry and wet conditions was 19.5 and $45.1 \mathrm{mg} / \mathrm{g}$, respectively. The other physically activated sample CC5PA was much less effective as $\mathrm{H}_{2} \mathrm{~S}$ adsorbent. The least effective were the chemically activated samples whose sorption capacity towards $\mathrm{H}_{2} \mathrm{~S}$ was very small and did not exceed $7 \mathrm{mg} / \mathrm{g}$. At the present state of knowledge we can only speculate about the reasons for such poor results obtained for the chemically activated samples. Most probably the reason is the presence of a large number of acidic groups on their surface, in contrast to the physically activated samples, and these groups are less inclined towards bonding $\mathrm{H}_{2} \mathrm{~S}$ than the basic functional groups present on the surface of samples CC5PA and CC8PA.

The data also reveal a pronounced effect of the conditions of $\mathrm{H}_{2} \mathrm{~S}$ adsorption on its efficiency. All carbonaceous materials studied showed much better sorption abilities upon adsorption in wet conditions. It should be noted that a modification of the adsorption conditions by preliminary wetting of the carbon bed with air of high humidity changes the sorption capacities of the samples studied in different ways. Preliminary wetting of adsorbent prior to adsorption in dry conditions increases the sorption capacity towards $\mathrm{H}_{2} \mathrm{~S}$, which is especially well seen for CC8PA. When the sorption capacity is measured in wet conditions the preliminary wetting of the adsorbent bed gives the opposite effect, so leads to deterioration of the sorption capacity.

Unfortunately, analysis of the curves illustrating changes in $\mathrm{H}_{2} \mathrm{~S}$ concentration upon adsorption in different conditions (Figs. 4 and 5) did not permit drawing conclusions on the reasons for such a low efficiency of $\mathrm{H}_{2} \mathrm{~S}$ removal by chemically activated carbons. The character of the majority of curves is similar. They have a flat section, when the adsorption curve overlaps the $\mathrm{x}$ axis and a characteristic point corresponding to the so-called breakthrough of the bed. Then the concentration of $\mathrm{H}_{2} \mathrm{~S}$ increases to a limiting
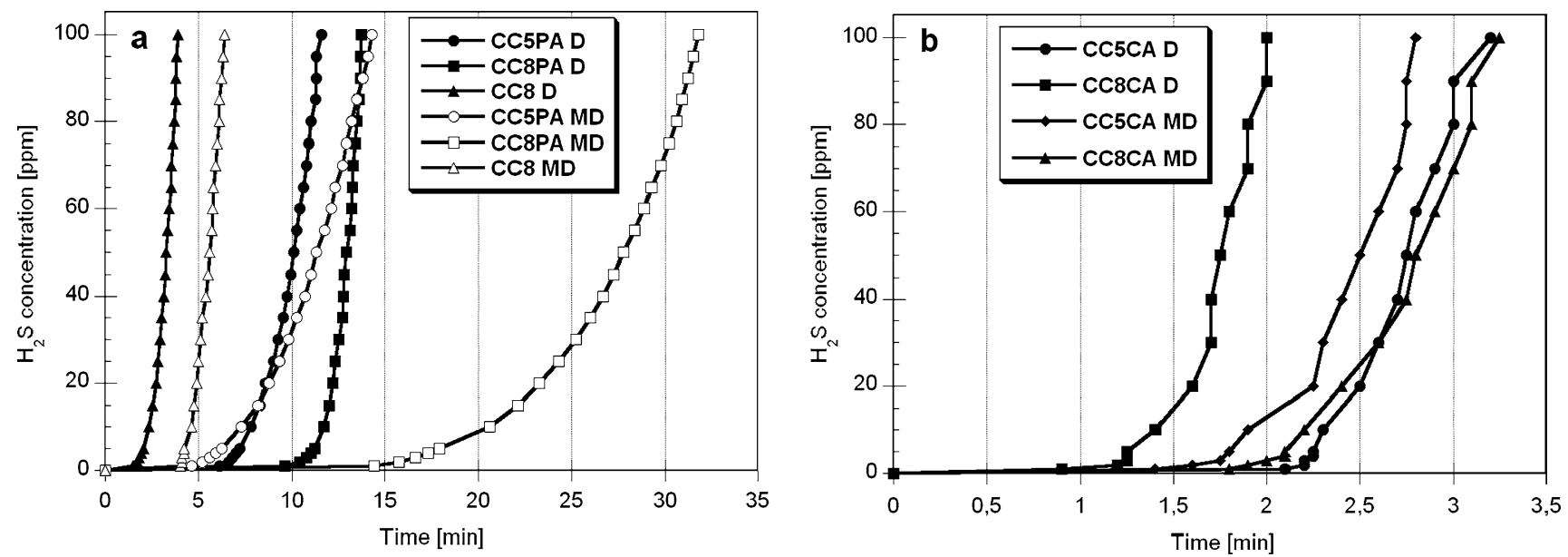

Fig. $4 \mathrm{H}_{2} \mathrm{~S}$ breakthrough curves for the chars and physically activated carbons (a) and chemically activated samples (b) recorded in the dry (D) and mix dry (MD) conditions
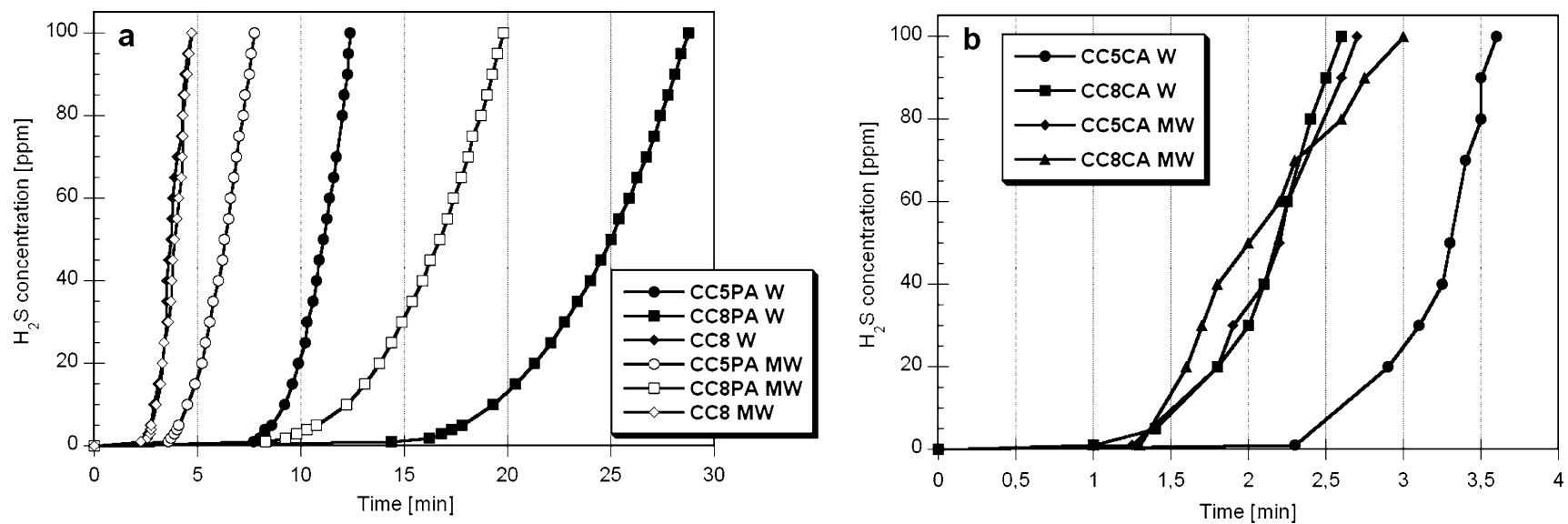

Fig. $5 \mathrm{H}_{2} \mathrm{~S}$ breakthrough curves for the chars and physically activated carbons (a) and chemically activated samples (b) recorded in the wet (W) and mix wet (MW) conditions 
Table 6 Adsorption of iodine and methylene blue on chars and activated carbons

\begin{tabular}{lll}
\hline Sample & $\begin{array}{l}\text { Iodine adsorption } \\
{[\mathrm{mg} / \mathrm{g}]}\end{array}$ & $\begin{array}{l}\text { Methylene blue adsorption } \\
{[\mathrm{mg} / \mathrm{g}]}\end{array}$ \\
\hline CC5 & 190 & 12 \\
CC8 & 530 & 6 \\
CC5PA & 680 & 18 \\
CC8PA & 890 & 78 \\
CC5CA & 1230 & 216 \\
CC8CA & 1360 & 270 \\
\hline
\end{tabular}

value (at $100 \mathrm{ppm}$ ), which is different for different samples and for different conditions of adsorption. For the majority of samples this fragment of the adsorption curve is close to a line rising in parallel to the $y$ axis. The only difference is that for chars and physically activated carbon samples (Figs. 4(a) and 5(a)) the curve is smooth, while for the chemically activated samples (Figs. 4(b) and 5(b)) it is rather irregular.

\subsection{Sorption abilities from liquid phase}

As follows from Table 6 data, the products of pyrolysis (especially CC8) show good sorption capacity towards iodine. No ability to adsorb methylene blue suggests that in the porous structures of the chars the dominant pores have small diameters and cannot adsorb large molecules. The temperature of pyrolysis has a great effect of the adsorption properties of the samples studied from the liquid phase. The increase in the pyrolysis temperature from 500 to $800{ }^{\circ} \mathrm{C}$ gives almost threefold improvement in the sorption capacity towards iodine. Unfortunately, the effect of pyrolysis temperature increase is almost undetectable in the process of adsorption of methylene blue. The adsorbents obtained by activation of the pyrolysis products (in particular chemical activation) show very high sorption capacities, both towards iodine and methylene blue. The iodine number of the activated carbons studied varies from 680 to $1360 \mathrm{mg}$, so at a level comparable to the values typical of commercial adsorbents. Moreover, carbons CC5CA and CC8CA, despite clearly microporous character, show very high sorption capacity towards methylene blue.

The sorption abilities towards iodine and methylene blue depend not only on the variant of activation but also on the temperature of pyrolysis. The higher the pyrolysis temperature, the higher the iodine and methylene numbers of the activated carbon samples.

\section{Conclusions}

The results presented and discussed above have shown that corn cobs can be successfully used as cheap and renewable precursor of activated carbon characterised by very good sorption properties towards gas and liquid pollutants. A proper choice of the parameters of chemical and physical activation of corn cobs, such as temperature, duration of activation, char/activator weight ratio, permits getting universal adsorbents showing very good sorption properties towards such pollutants as $\mathrm{NO}_{2}, \mathrm{H}_{2} \mathrm{~S}$ and liquid organic pollutants, however more studies are needed.

Open Access This article is distributed under the terms of the Creative Commons Attribution License which permits any use, distribution, and reproduction in any medium, provided the original author(s) and the source are credited.

\section{References}

Bansal, R.C., Goyal, M.: Activated Carbon Adsorption. Taylor \& Francis, Boca Raton (2005)

Boehm, H.P., Diehl, E., Heck, W., Sappok, R.: Surface oxides of carbon. Angew. Chem., Int. Ed. Engl. 3, 669-677 (1964)

Cao, Q., Xie, K., Lv, Y., Bao, W.: Process effects on activated carbon with large specific surface area from corn cob. Bioresour. Technol. 97, 110-115 (2006)

Chang, C.F., Chang, C.Y., Tsai, W.T.: Effects of burn-off and activation temperature on preparation of activated carbon from corn cob agrowaste by $\mathrm{CO}_{2}$ and steam. J. Colloid Interface Sci. 232, 45-49 (2000)

Deryło-Marczewska, A., Goworek, J., Świątkowski, A., Buczek, B.: Influence of differences in porous structure within granules of activated carbon on adsorption of aromatics from aqueous solutions. Carbon 42, 301-306 (2004)

Elizalde-González, M.P., Mattusch, J., Pelaez-Cid, A.A., Wennrich, R.: J. Anal. Appl. Pyrolysis 78, 185-193 (2007)

Foo, K.Y., Hameed, B.H.: Microwave assisted preparation of activated carbon from pomelo skin for the removal of anionic and cationic dyes. Chem. Eng. J. 173, 385-390 (2011)

Foo, K.Y., Hameed, B.H.: Factors affecting the carbon yield and adsorption capability of the mangosteen peel activated carbon prepared by microwave assisted $\mathrm{K}_{2} \mathrm{CO}_{3}$ activation. Chem. Eng. J. 180, 66-74 (2012)

Jiang, H., Chen, H.: Research on preparation of activated carbon from agricultural wastes and analysis of pore structure. Energy Procedia 11, 3629-3633 (2011)

Kutahyal1, C., Eral, M.: Sorption studies of uranium and thorium on activated carbon prepared from olive stones: kinetic and thermodynamic aspects. J. Nucl. Mater. 396, 251-256 (2010)

Lee, W.H., Reucroft, P.J.: Vapor adsorption on coal- and wood-based chemically activated carbons (III) $\mathrm{NH}_{3}$ and $\mathrm{H}_{2} \mathrm{~S}$ adsorption in the low relative pressure range. Carbon 37, 21-26 (1999)

Olivares-Marín, M., Fernández, J.A., Lázaro, M.J., FernándezGonzález, C., Macías-García, A., Gómez-Serrano, V., Stoeckli, F., Centeno, T.A.: Mater. Chem. Phys. 114, 323-327 (2009)

Özçimen, D., Ersoy-Meriçboyu, A.: Removal of copper from aqueous solutions by adsorption onto chestnut shell and grapeseed activated carbons. J. Hazard. Mater. 168, 1118-1125 (2009)

Rosas, J.M., Bedia, J., Rodríguez-Mirasol, J., Cordero, T.: On the preparation and characterization of chars and activated carbons from orange skin. Fuel Process. Technol. 91, 1345-1354 (2010)

Sevilla, M., Fuertes, A.B., Mokaya, R.: Preparation and hydrogen storage capacity of highly porous activated carbon materials derived from polythiophene. Int. J. Hydrog. Energy 36, 15658-15663 (2011) 
Soleimani, M., Kaghazchi, T.: Adsorption of gold ions from industrial wastewater using activated carbon derived from hard shell of apricot stones - an agricultural waste. Bioresour. Technol. 99, 53745383 (2008)

Solisio, S., Lodi, A., Del Borghi, M.: Treatment of effluent containing micropollutants by means of activated carbon. Waste Manag. 21, 33-40 (2001)

Sych, N.V., Trofymenko, S.I., Poddubnaya, O.I., Tsyba, M.M., Sapsay, V.I., Klymchuk, D.O., Puziy, A.M.: Porous structure and sur- face chemistry of phosphoric acid activated carbon from corncob. Appl. Surf. Sci. 261, 75-82 (2012)

Tsai, W.T., Chang, C.Y., Wang, S.Y., Chang, S.F., Chien, C.F., Sun, H.F.: Cleaner production of carbon adsorbents by utilizing agricultural waste corn cob. Resour. Conserv. Recycl. 32, 43-53 (2001)

Tsai, W.T., Chang, C.Y., Lee, S.L.: A low cost adsorbent from agricultural waste corn cob by zinc chloride activation. Bioresour. Technol. 64, 211-217 (1998) 